MEMÓRIA

\title{
Política de Ciência e Tecnologia no I PND (1972/74) e no I PBDCT (1973/74)
}

Sergio SallesFilho

FINEP E DPCT/UNICAMP

"A revolução tecnológica, principalmentenasúltimas décadas, repercute profundamente sobre o desenvolvimento industrial eo comércio internacional, passando o crescimento econômico a ser cada vez mais determinado pelo progresso tecnológico."

D eve-se dar "prioridade à articulação do sistema de ciência etecnologia com o setor produtivo, com a programação governamental ecom as realidades da sociedade brasileira atual. A integração entreaquelesistemaeas diferentes dimensões da sociedadeem mudança permitiráa conseqüenteefecundainteração".

"A interação indústria-pesquisa-universidade(será) impulsionada medianterealização de programas conjuntos de pesquisa, em setores prioritários e, em grande dimensão, com participação deinstituições governamentais de pesquisa, universidadesesetor privado (...)."

"A fim depossibilitar a coordenação das unidades componentes, deverão ser constituídos sistemas setoriaisbasicamentecom os seguintesobjetivos:

- formulação de diretrizes gerais de política depesquisa em cadaárea correspondente;

- elaboração dos programassetoriaisdepesquisas;

- acompanhamento deprogramaseprojetossetoriaisespećificos."

Trechos extraídos do Primeiro Plano Nacional de Desenvolvimento (1972-74) e do Plano Básico de Desenvolvimento Científico e Tecnológico (1973-74).

Ao tempo em quea política de ciência etecnologia amplia seu espaço no cenário nacional, abrindo perspectivas etransformando atitudesé, por muitos motivos, recomendável lançar um olhar sobre a história recente do País. As apostas no futuro que hoje estamos fazendo não precisam ser explicadas com base no passado (e não seria difícil analisá-las tomando-se exclusivamente a conjuntura e o momento histórico que se vive). 
Ao definir a política, olhamos quase sempre para a frente- o queébom, pois queremos um certo futuro. Um bom diagnóstico na mão, aliado a um bom conhecimento do que anda por aí, nos permite traçar um cenário para 0 futuro - etomar atitudes para al cançá-lo. Convencer as pessoas disso éparte do trabal ho. Parte dura, diga-se depassagem. N ada contra, muito pelo contrário...

Entretanto, quando al gumas idéias se mostram recorrentes (mesmo que em circunstânciaserealidades diferentes), amemória ajuda a estabelecer contornos importantes. Examinar o que se passou com essasidéias e suas conseqüências ao longo da história é um tema, em si, atraente. N ão se trata de buscar lições no passado (ainda queal gumas possam ter validade no presente), trata-sebem mais de um estímulo intelectual que, explorado, pode trazer revelações valiosas (ou no mínimo úteis para que a memória seja fixada). Sem ela - a memória podemos, involuntariamente, tropeçar na recorrência dos fatos. Ademais, fica sempre mais fácil convencer as pessoas a aderirem a uma certa direção se essa memória for bem anal isada e der explicações convincentes de por que diabos não conseguimos outrora fazer valer idéias que hoje nos parecem tão... elementares. É certo que as idéias eas políticas têm o seu lugar e o seu tempo. M as dizer simplesmente quefoi equívoco detimingé, no mínimo, insatisfatório.

Com o intuito de estimular a análise (comparativa ou não) sobre o que se passou e o que se passa na política de ciência e tecnologia do País, a RB I publicará uma série de documentos relacionados a diferentes momentos da política nacional de $C \&$ T. N estenúmero, reproduzimos parte do Plano Básico deD esenvolvimento Científico eTecnológico, publicado em 1973. Instrumento organizado e consolidado, o PBDCT definia diretrizes muito claras sobre os rumos que deveriam tomar o desenvolvimento científico e tecnológico do País. Escrito em estrita coerência com as propostas de desenvolvimento nacional de então, este PBD CT daria origem a uma série de três documentos de mesmo objetivo (I, II elII PBDCT).

M aspor qual razão esteenão outro documento histórico?Bem, os trechos acima oferecem uma boa dica. Algumas das tais idéias recorrentes a quefizemos menção podem, comparadas aos rumos da política de hoje, ser identificadas. Por exemplo, há uma explícita proposição de que o apoio a $C \& T$ deveria se referir ao plano de desenvolvimento econômico do País. M ais do que isso, era clara aintenção de promover a relação entrea pesquisa, a universidadee empresa, 
tema esse, sem dúvida, recorrente, eainda não devidamente equacionado. Falase do fomento ao investimento privado em tecnologia e da necessidade de interagir o conhecimento (a ciência) gerado nas instituições de pesquisa e universidades com as necessidades do setor privado.

Como atrair o investimento de empresas estrangeiras em pesquisa também pautava o PBDCT, assim como a necessidade de construção de um sistema integrado, contando com vários agentes com capacidade de mobilizar recursos para incorporar, adaptar e gerar tecnologia no seio da indústria eda agricultura. Como se sabe, esses são temas hoje importantes no esforço de promoção da inovação. 0 leitor poderá constatar que, embora pouco usada naquele momento, a palavra inovação já fazia parte do vocabulário. Logicamente, há diferenças entre o de ontem e o de hoje, mas quais são exatamente essas diferenças e por que essas idéias vêm nos desafiando por tanto tempo são questões sobre as quais vale se debruçar em um esforço analítico.

0 II PBDCT, que será reproduzido em parte no próximo número da Revistaé, nesse sentido, ainda mais interessante. Assim, a RB I lança a proposta de receber contribuições de seus leitores para esse esforço analítico. Artigos que se aprofundem no tema poderão ajudar a consolidar e interpretar a memória da política.

Boaleitura. 


\section{Plano Nacional de Desenvolvimento (PND) - 1972/74*}

\section{Capítulo II}

\section{Os Fatores da Expansão: Política Científica e Tecnológica}

A revolução tecnológica, principalmentenasúltimas duas décadas, repercute profundamente sobre o desenvolvimento industrial e o comércio internacional, passando o crescimento econômico a ser cadavez mais determinado pelo progresso tecnológico. I sso altera as vantagen s comparativas entre os países, em diferentes setores, pelas reduções drásticas em custos detransportes, pelo uso desucedâneos sintéticos eoutras al terações na estrutura decustos.

As novas áreas tecnológicas em progresso rápido - a energia nuclear, a eletrônica, a pesquisa espacial - exigem, a seu turno, investimentos maciços para desenvolver tais setores.

Além disso, registra-se a presença crescente da empresa multinacional. N os anos 60, as empresas americanas cresciam mais rapidamente na Europa do que nosEstados U nidos, eas principais empresas européias, maisnosEstadosUnidos do quenaEuropa.

$\mathrm{N}$ a estratégia tecnológica para o Brasil, importa:

1) Fortalecer o poder de competição nacional, em setores prioritários, entre os quais, certas indústrias, cuidadosamente selecionadas, de alta intensidade tecnológica. É preciso suplementar a importação detecnologia com a adaptação tecnológica eo esforço decriação própria.

0 aumento do poder competitivo da indústria nacional, indispensável à expansão de mercado, interna e externamente, depende de maior esforço de elaboração tecnológicainterna. A incorporação da chamadaengenharia deproduto e de processo, para criar modelos e processos nacionais, permite, de um lado, melhor adaptação dos produtos às condições de demanda e, de outro, melhor aproveitamento dasvantagenscomparativas do País, quanto a custos de produção. É necessário, deoutra parte, resolver problemastecnológicospróprios, notadamente quanto à indústria, agricultura epesquisa de recursos minerais.

\footnotetext{
* O presente texto é uma reprodução fiel do publicado no Suplemento do Diário Oficial de 17 de dezembro.
} 
2) Concentrar recursos em prioridades tecnológicas claras, diante da impossibilidade de cobrir todo o espectro de novas áreas tecnológicas. Além de exigirem base deaptidão tecnológica geral, as aplicações devem concentrar-seem áreas e projetosselecionados, para uma real ização eficiente, em escala adequada, com capacidade de competição. D ar-se-á caráter realmente estratégico - ou seja, não diluído - à política tecnológica brasileira, de modo que assegure a nossa participação em "setores de ponta", altamente intensivos de tecnologia, em tranfformação acelerada ecom perspectiva dealtastaxas de crescimento.

A execução dessa estratégia, que dá ênfase à aceleração e orientação da transferência detecnologia, associada a fortecomponentedeelaboração tecnológica própria, sefarásegundo esteprograma, estabelecido para o período 1972/74:

I - 0 de ordenar eacelerar a atuação do governo, mediante:

- O peração do sistema financeiro para o desenvolvimento tecnológico, compreendendo, notadamente, o Fundo $\mathrm{N}$ acional deD esenvolvimento C ientífico eTecnológico (FNDCT), o FUNTEC (BNDE), o fundo associado ao Conselho N acional dePesquisas (CN Pq) eo FUN AT (INT). Esseconjunto defundos deverá realizar, no período, aplicações de C r\$ 1.100 milhões (preços de 1972).

- Coordenação da atuação e modernização das principais instituições governamentais de pesquisa científica e tecnológica, para executar o PLAN 0 BÁSICO DE DESEN VOLVIM ENTO CIENTÍFICO E TECNOLÓGICO, quedeverá aplicar, no período, Cr\$1.750 milhões, ou seja, a média anual de C $\$ 583$ milhões, em comparação com Cr\$ 90 milhões, em 1968 (a preços de 1972).

A mobilização de recursos externos permitirá o reforço do programa de fortalecimento deum conjunto selecionado deinstituiçõese centros de pesquisas federais, estaduaise privados, dedicadosà solução de problemas tecnológicosda indústria.

Incumbido de promover e coordenar o programa geral, em articulação com o M inistério do Planejamento eC oordenação Geral, o Conselho N acional de Pesquisas (CN Pq) está tendo a sua estrutura fortalecida e modernizada. O s diferentes M inistériosjá selecionaram osórgãosa serem fortalecidosinstitucional efinanceiramente, na primeira fase, como principaisinstrumentos do PBDCT.

- Revigoramento da carreira depesquisador, nas principaisinstituições de 
pesquisa do G overno Federal (administração direta e autarquias), demodo que permita condições de trabal ho adequadas, preferencialmenteem tempo integral, com regimederemuneração satisfatório ecom perspectivas deascensão funcional. Comissão integrada pelo M inistério do Planejamento e Coordenação Geral, DASP eCN Pq irá propor as bases dessa reformulação.

- Implantação do Sistema N acional de Informação Científica e Tecnológica, funcionalmente articulado com o CN Pq e para operação decaráter descentralizado.

O s principais componentes deverão ser os subsistemas de Informação Científica, de Informação Tecnológica Industrial Livre, de Informação Tecnológica Patenteada (com criação do Banco de Patentes), de Informação sobre I nfra-estrutura eServiços, deI nformação Agrícola edeC oleta eD isseminação delnformações do Exterior.

II - 0 de desenvolver áreas tecnológicas prioritárias, compreendendo:

- Incorporação denovas tecnologias, principalmente: Energia N uclear, Pesquisa Espacial, 0 ceanografia.

- D esenvolvimento de indústrias intensivas de tecnologia, como a Indústria Q uímica, Indústria Eletrônica, Siderurgia, Indústria Aeronáutica (primeira fase), com ampliação simultânea da capacidadeinterna de pesquisas.

- Consolidação daTecnologia de Infra-estrutura, no tocantea Energia Elétrica, Petróleo, Transportes, Comunicações.

- Programa Intensivo de Pesquisa Agrícola, notadamente com relação às principais culturas, à agricultura de "cerrados", às técnicas de irrigação, eà tecnologia dealimentostropicais.

O G overno Federal deveráimplantar, na G uanabara, complexo tecnológico quereunirá os centros detecnologia das principaisempresas einstituiçõesfederais, notadamentequanto àinfra estrutura eindústrias básicas. Essecomplexo incluirá, entreoutros, osC entros deTecnologiadePetróleo, deEnergiaElétrica, dePesquisa M ineral, dePesquisa N uclear, deTelecomunicações edel nformática.

III - 0 defortalecer a infra-estrutura tecnológica ea capacidade deinovação da empresa nacional, privada e pública, mediante: 
- Criação da grande empresa nacional, e empresas multinacionais brasileiras (isoladamente ou em associação com capitais externos), para promover exportações em setores de tecnologia complexa.

- Política de M odernização Tecnológica e Administrativa da empresa nacional, privada e governamental.

- Incentivos à inovação dentro da empresa, mediante: cooperação financeira do G overno às instituições de pesquisa criadas pela iniciativa privada; política de induzir as empresas estrangeiras a dotarem suas subsidiárias no B rasil de orçamentos plurianuais da pesquisa; financiamento a longo prazo de pesquisas de interesse das empresas; isenções fiscais à compra de equipamentos para laboratórios de pesquisas, importados ou de fabricação nacional; isen ções fiscais para certos tipos de dispêndios realizados em pesquisa pelas empresas.

IV - O deacelerar a transferência detecnologia, com política depatentes, interna e externa.

A política de aceleração de transferência de tecnologia basear-se-á em conhecimento bastante preciso dos requisitos tecnológicos do sistema produtivo e da potencialidade da produção nacional de ciência e tecnologia. Estabelecer-se-á, para isso, estrutura institucional suficientementeflexível para avaliar cada caso específico.

Serão definidos os setores prioritários para transferência de tecnologia que considere tanto o confronto entre demanda interna e oferta interna de "know-how" quanto a natureza da produção do setor e sua importância para o cumprimento das diretrizes de política econômica. É necessário, também, que o tratamento legal possa distinguir, claramente, entreas diversas categorias detransferência: assi stência técnica permanente, assistência técnica temporária, licença para utilização de patentes, licença para utilização de marcas e projeto de investimento completo. 0 s contratos de transferência submetidos a registro devem ser examinados pelos organismos competentes, tendo em vista a avaliação da necessidade da importação da tecnologia, a adequabilidade da remuneração prevista consoante as condições do mercado mundial e a importância, para o País, da tecnologia a ser transferida. A legislação quanto a 
remessas relativas à contratação de know-how poderá estabelecer tratamento diferenciado por setores, consoantea capacidadenacional de elaboração própria.

V - O deintegrar Indústria-PesquisaU Universidade, como núcleo fundamental deuma estrutura nacional integrada deE ducação/Ciência-Tecnologia/Empresa.

Essa integração deverá ser impulsionada mediante:

- D isseminação econsolidação dos centros de integração UniversidadeIndústria ou Escola-E mpresa, para assegurar programas sistemáticos de estágios de estudantes em empresas, para comunicar ao sistema universitário as necessidades quantitativas equalitativas do setor privado quanto à formação de profissionais, epara permitir a realização conjunta de projetos de pesquisa.

- Adoção, pelasinstituições de pesquisa governamentais, de programa sistemático de articulação com o setor produtivo nacional, principalmente para disseminação do resultado de seus estudos.

- Real ização de convênios do G overno com as U niversidades, para que estas procedam (isoladamente, ou em conjunto com entidades governamentais) a estudos de desenvolvimento regional, ou a pesqui sas aplicadas, de interesse do planejamento econômico e social.

- Ampliação dos esquemas de participação do estudantenosprogramas de desenvolvimento, a exemplo do Projeto Rondon, da O peração M auá e do Projeto Integração. 


\section{PBDCT - Plano Básico de Desenvolvimento Científico e Tecnológico - 1973/74}

Pronunciamento do M inistro do Planejamento e Coordenação G eral, João Paulo dos Reis Velloso, na reunião de lançamento do Plano Básico de D esenvolvimento Científico e Tecnológico - 1973/1974, sob a Presidência do Excelentíssimo Senhor Presidente da República, Gen. Emílio G arrastazu M édici, em 25-07-73, com a presença dos Senhores G en. J oão Batista de O liveira Figueiredo, Chefe do $G$ abinete M ilitar da Presidência da República, D r. João Leitão deAbreu, Chefedo G abineteCivil da Presidênciada República, Gen. Carlos Alberto da Fontoura, C hefe do Serviço N acional de Informaç̧ões, G en. Arthur $\mathrm{M}$ ascarenhas Façanha, Presidentedo Conselho $\mathrm{N}$ acional de Pesquisas, Prof. $\mathrm{O}$ scar Scalla, Presidente da Sociedade Brasileira para o Progresso da Ciência, Prof. Aristides Azevedo Pacheco Leão, Presidenteda Academia Brasileira deC iências eD r. JoséPelúcio Ferreira, Presidenteda Financiadora deEstudoseProjetosS.A.

\section{Senhor Presidente:}

O sentido essencial destePlano Básico de D esenvolvimento Científico e Tecnológico (PBDCT) - 1973/1974, que nesta oportunidade éaprovado por VossaExcelência, écolocar a ciência etecnologia modernas a serviço da sociedade brasileira, nos seus objetivos de desenvolvimento e degrandeza.

Em verdade, o progresso científico e tecnológico está para o Brasil dos anos 1970 como a emergência do processo de industrialização estava para o Brasil do imediato pós-guerra. Trata-senão de um programa setorial, por mais importanteque seja, mas de uma força motora. É o conduto, por excelência, da idéia de modernização, essencial à consolidação de uma economia poderosa e competitiva, mas não menos importante em relação às demais vertentes dominadoras da estratégia de desen volvimento do G overno deVossa Excelência.

I mportante para a humanização da vida urbana, para a superação da agricultura tradicional; para a realização dos objetivos de integração nacional, efetivando a conquista econômica do universo brasileiro notadamente com referênciaà Amazôniaeao $\mathrm{N}$ ordeste; para aação social nos campos daEducação, Saúde-Saneamento, N utrição; paraa consecução da mehor distribuição de renda através do próprio crescimento. 
N esse sentido, o Plano representa a nota que faltava, o complemento indispensável da tarefa de pragmatismo reformista que a Revolução vem empreendendo.

É sabido que nada está mais presente na vida do homem moderno, e nada mais relevante para dimensão humana da sociedade urbanizada e industrializada de nossos tempos do que a ciência e tecnologia. É ela capaz, como em nenhuma outra época, deampliar dramaticamente as oportunidades de acesso do grande número aos bens e serviços que a produção em larga escala democratiza. Bens e serviços que, em outros tempos, eram domínio de poucos: apenas como exemplo, há um século atrás a anestesia era privilégio dos rei s; ejá se observou que, em termos de conforto cotidiano, uma família de classe média de país desenvolvido, hoje, revela padrão de vida superior ao deLuísXIV.

Por outro lado, nada, como a ciência e tecnologia, é mais suscetível de gerar desencanto e angústia à sociedade em transformação em que vivemos, particularmente, na fase deintensa urbanização de um país, como o nosso, que cresce a $10 \%$ ao ano.

N a análise do Plano Básico, o primeiro ponto a destacar, é a definição, para o País, de uma política de ciência etecnologia que lhe permita acompanhar o progresso científico mundial, obter, para os setores prioritários, a tecnologia mais atual izada emontar internamente uma estrutura capaz de, gradualmente, passar a produzir tecnologia, enão apenas de produzir bense serviços.

Com efeito, já se assinal ou que a forma mais segura de manter um país subdesenvolvido indefinidamenteésemprepôr à sua disposição uma tecnologia pronta eacabada. Chegou, para o nosso desenvolvimento, o estágio de realizar adaptações e de, racional e competitivamente, iniciar em certos setores a elaboração demodelos eprocessosmais sadequadosao nosso esforço de expansão do mercado interno e impulsionamento das exportações, dentro de decisões econômicas inteligentes que considerem a nossa relativa dotação de fatores de produção, principal mente quanto à mão-de-obra ea nossa disponibilidade de recursosnaturais próprios.

Aquela política científica e tecnológica, destinada a fazer atuar orgânicae coordenadamente todo o sistema nacional de ciência e tecnologia, tem como principais linhas de atuação: o desenvolvimento de novas tecnologias (energia 
nuclear e pesquisa espacial aplicadas ao desenvolvimento, oceanografia); 0 desenvolvimento de novas indústrias intensivas de tecnologia (Eletrônica, Q uímica, Aeronáutica); o fortalecimento da capacidade de absorção e criação de tecnologia pela empresa, pública eprivada, para engajar o setor produtivo no processo; a consolidação da infra-estrutura de pesquisa científica e tecnológica, principalmente na área governamental, para aparelhá-la a funcionar segundo processos modernos de gestão empresarial, fortalecida financeira e institucionalmente; ea integração entreindústria, pesquisa euniversidade, por programas real istas e objetivos.

Em segundo lugar, o Plano Básico tem dimensão capaz de produzir impacto, através de dispêndios federaisno biênio da ordem de $\mathrm{C}$ r $\$ 4,3$ bilhões (preços de 1973), ou seja C $\$$ 2,150 bilhões por ano.

O ra, o G overno Federal aplicava no setor, há cinco anos atrás, al go da ordem de Cr\$100 milhões por ano. E o próprio Plano $\mathrm{N}$ acional de D esenvolvimento (PND), em 1971, previa para o PBDCT recursos anuais em torno de Cr\$ 670 milhões (a preços de 1973).

Como indicação da ordem de grandeza do programa brasileiro, pode-se mencionar que o programa global de apoio técnico da O NU a todo o mundo subdesenvolvido, relacionado, primordialmente, com as áreas tecnológica ede pesquisa científica, correspondeà ordem deU S\$ 300 a U S\$ 320 milhões anuais, ou seja, cerca de C r\$1,8 a C r\$1,9 bilhões (preços de 1973).

$\mathrm{N}$ aquele montante de aplicação do Plano Básico, cabe destacar os recursos destinadosàTecnologia Industrial, em sentido amplo, compreendendo a Tecnologia de Infra-estrutura (Energia, Transportes e Comunicações), com C r\$ 420 milhõesno biênio, ea das I ndústrias deTransformação (notadamente, Indústrias Básicas), com Cr\$1,2 milhões. É um esforço dramático para a construção do sistema de centros de tecnologia, em empresas de G overno e em áreas privadas, capaz desituar o País em posição adulta no campo da competição industrial moderna. I sso dará bases permanentes e sólidas ao impulso que já permiteao País, hoje, exportar computadores eletrônicos de grande porte(com mais de $50 \%$ do valor adicionado no País), navios e, em breve, locomotivas; absorver a tecnologia da construção de metrôs, construir supergraneleiros de 400.000 toneladas e aviões e carros esporte com modelo próprio; exportar serviços de consultoria eengenharia em áreas de infra-estrutura. 
Importantes são, também, entre outros, o programa deTecnologiaAgrícola (com C r\$ 480 milhões), principalmentenosinúmerosprojetos detecnologia de alimentos, eo voltado para o campo da Integração $\mathrm{N}$ acional, através de projetos como o deTrópico Ú mido, o de "Cerrados" e o Projeto Aripuanã. Esteúltimo permitirá, ainda esteano, a construção de uma pequenacidadecientíficano coração da floresta amazônica, para conhecer-Ihe os segredos de riqueza florestal, mineralogia, solos, equilíbrio ecológico.

A pesquisa fundamental, ligadaà pós-graduação na universidade, receberá recursos de cerca de $\mathrm{Cr} \$ 900$ milhões.

Em terceiro lugar, o Plano Básico está dotado deinstrumentos poderosos, que respondem pela sua viabilidadee realismo deobjetivos. Instrumentos como o sistema de fundos especiais - o fundo do Consel ho $\mathrm{N}$ acional de Pesquisas, 0 FUNTEC, do BNDE, O FNDCT, que opera como fundo dos fundos, no setor - , voltados para o financiamento de projetos prioritários e para o fortalecimento sistemático dasinstituições consideradas básicas, naárea dos diferentes $M$ inistérios. Ao lado disso, está proposta por Vossa Excelência ao Congresso Nacional a estruturação, dentro do novo sistema de classificação de cargos, do G rupo de Pesquisa Científica eTecnológica, configurando a carreira em tempo integral do pesquisador, na maisalta escala deremuneração do sistema de pessoal civil.

Para engajar na política tecnológica a empresa privada, garante-se sistema de incentivos de origem financeira e, proximamente, fiscal. O G overno, pelos mecanismosjámontados, apoiarátodas as iniciativas válidas daárea empresarial, objetivando consolidar a capacidadenacional em engenharia de projeto edesenho industrial, assim como já vem operando importantes programas que subsidiam a modernização tecnológica e de capacidade industrial para a empresa privada nacional.

\section{Senhor Presidente:}

EstePlano Básico deD esenvolvimento Científico eTecnológico, elaborado através da cooperação entretodosos M inistros do G overno de Vossa Excelênciae em cuja coordenação teve papel de relevo o Conselho $\mathrm{N}$ acional de Pesquisas, é importante para o progresso econômico brasileiro e, mais queisso, para o bemestar da sociedadebrasileira. 
Com organicidade e adequado arsenal de instrumentos pode, agora, 0 G overno operar, articulado com o setor produtivo.

Sem embargo, seus objetivos não serão atingidos sem a compreensão, confiançaesolidariedadedoshomensquefazem ciênciaetecnologianasinstituições de pesquisa e nas universidades. D os cientistas etecnólogos brasi leiros, o que se desejaéa atitude departicipação, dentro da convicção dequetodossomoshomens de trabal ho - no Governo, na empresa, no laboratório, na universidade- , com uma tarefa a executar eresponsabilidade pela qual responder à $\mathrm{N}$ ação.

Interessa, ao País, não a existência deum mundo dicotômico - a economia em contrastecom a ciência, a universidadeem contrastecom a sociedade. Interessa, sim, a realidade de uma sociedade indivisa e solidária, empenhada na tarefa de compatibilizar o progresso vertiginoso e a dimensão de potência a que o Brasil está votado com os val ores culturais ehumanos de uma experiência social que, até hoje, soube evitar a criação de problemasinsolúveis, aliando à ambição de crescer a sabedoria da não-violência, da al egria de viver, da oportunidadepara todos, do respeito ao senso de individualidade e ao desejo de realização própria - os ingredientes quefazem as sociedades prósperas, inteligentese humanas. 


\section{Capítulo 1}

\section{O Plano Básico e a Política de Ciência e Tecnologia}

A transformação econômica esocial, na sociedademoderna, passou a ser de tal modo condicionada pela ciência etecnologia queo domínio destas representa, atualmente, fator fundamental na determinação do poder de competição relativo dos diferentes países.

0 efeito da revolução tecnológica sobre o desenvolvimento econômico e social semanifesta principalmente sob as seguintesformas:

1) 0 crescimento econômico tendea ser cada vez mais determinado pelo progresso tecnológico, que, em escala crescente, dá origem a novas indústrias, novos produtos, novos materiais (inclusive sucedâneos de matérias-primas naturais), alterando as estruturas de demanda edecustos.

2) 0 progresso tecnológico modifica rapidamenteas estruturas deprodução ede "management", levando, em particular, juntamentecom fatores econômicos efinanceiros, ao advento dos projetosem grandeescala, dosconglomerados, das empresasmultinacionais.

3) O sprogressos realizadosna navegação marítima eaérea- particularmente o surgimento dos supernavios - enas comunicações vêm alterando as vantagens comparativas entreospaíses.

4) N uma sociedade predominantementeurbana, osproblemas detrânsito, automação, poluição, passaram a afetar crescentementea vida decadaindivíduo.

A definição deuma política de ciência e tecnologia para o Brasil significa a suautilização a serviço dos grandesobjetivos da sociedadebrasileira, e, em particular, do desenvolvimento baseado na associação inteligente entre cultura humanista moderna etecnologia. No campo econômico, tem o sentido de capacitar o País a, progressivamente, passar a produzir tecnologia, enão apenas bens deconsumo ou deprodução.

N o próximo estágio, estará o País empenhado, essencialmente, em:

- Construir, uma economia para os anos 70. Economia moderna e 
dinâmica, que permita ao País enfrentar a competição econômica etecnológica denossos dias, equerepresentaráo advento, entrenós, da sociedade industrial, sem prejuízo dos valores humanos da sociedade brasileira.

Realizar as duas aberturas em que se vem empenhando 0 atual G overno: a regional, com a interação do $\mathrm{N}$ ordeste e da Amazônia; e a social, com a disseminação dos resultados do crescimento acelerado ea criação progressiva do mercado de massa.

Em face desses objetivos nacionais, a definição de política acima referida vai implicar não apenas em ter a ciência etecnologia atuando na aceleração do crescimento industrial eagrícola, na modernização das estruturas empresariais do País, na expansão das exportações, na procura denovosmétodos de prospecção e processamento de minerais - funções eminentemente econômicas; mas também na humanização das cidades, no avanço da tecnologia dealimentos de uso popular, na solução de problemas de saúde específicos do País, na batal ha da integração nacional, quer pelo Programa de Pesquisa do Trópico Ú mido, quer pelos programas de pesquisa ligados ao Trópico Árido - 0 N ordeste.

Em todo esse esforço de colocar a ciência e tecnologia a trabal har pelos grandes objetivos nacionais, ter-seá em mentea função atribuída ao progresso tecnológico: apoiar o processo de colocar à disposição do grandenúmero, pela produção em grande escala ea baixos custos, com ganhos de produtividade que sejam divididos com o consumidor, um volume crescente de bens e serviços, notadamenteos produtos manufaturados.

Importante será, também, a associação da política tecnológica com a política de emprego, em bases nacional e regional, visando a assegurar a compatibilidade daquela com o objetivo de expandir 0 emprego ataxassuperiores a 3\% ao ano, para absorver a mão-de-obra adicionalmente disponível no mercado de trabal ho e para reduzir os índices de subemprego ainda existentes em setores ou regiões.

Tendo em vistaa estruturaindustrial etecnológicaqueo Paísjáconstruiu, e 0 estágio de desenvolvimento em que nos encontramos, afigura-se viável a implementação de uma estratégia tecnológica baseada nos seguintes pontos:

1) Como orientação geral: aceleração edirecionamento da transferência de tecnologia do exterior, ao lado do esforço de fortal ecimento da capacidade 
de inovação tecnológica própria. $\mathrm{N}$ as Indústrias Básicas, sempre com a preocupação de consolidar o seu poder de competição, o País procurará atualizar-se nas mais modernas alternativas tecnológicas disponíveis, e definirá prioridades nítidas para, racionalmente, ingressar progressivamente em novos setores, intensi vos de tecnologia. Ao mesmo tempo, identificará os campos e produtos em que se faz possível realizar adaptações tecnológicas e, mesmo, elaborar internamente modelos e processos.

D ar-se-á ênfase ao desenvolvimento de forte capacitação nacional em "engineering" e "industrial design". Em grande número de setores, o País já está tecnicamente apto a fazer 0 detalhamento dos projetos industriais, elaborando a especificação dos equipamentos.

2) No campo das novas áreas tecnológicas, que em geral exigem investimentos de grande dimensão e al to risco - Energia N uclear, Pesquisa Espacial, Cibernética, 0 ceanografia -, orientação de: (1) enfoque eminentemente aplicado aos problemas concretos do desenvolvimento nacional; e (2) atuação segundo prioridades rigorosamente estabelecidas, em programas e projetos bem definidos, dentro delimites financeiros prefixados. $M$ ais que em outras áreas, conferir-se-á caráter realmente estratégico - ou seja, não diluído - à atuação com recursos governamentais nesse campo.

3) Prioridade à articulação do sistema de ciência e tecnologia com o setor produtivo, com a programação governamental e, em geral, com as realidades da sociedade brasileira atual. A integração entre aquel esistema eas diferentes dimensões da sociedade em mudança permitirá a conseqüente e fecundainteração.

A política científica e tecnológica a ser implementada compreende as seguintes principais áreas de atuação:

I - D esenvolvimento de novas tecnologias, notadamente as atividades que incorporem tecnologia de natureza interdisciplinar e ao mesmo tempo avançadas: Energia N uclear aplicada ao desenvolvimento; Pesquisa Espacial aplicada ao desenvolvimento; O ceanografia. D esenvolvimento de $\mathrm{N}$ ovas Indústrias, intensivas de tecnologia: Indústria Aeronáutica, Indústria Q uímica, Indústria Eletrônica (e, em particular, Indústria de Computadores). 
II - Fortalecimento da capacidade de absorção e criação de tecnologia pela empresa nacional, pública e privada. 0 engajamento efetivo da empresa na política tecnológica, para fortalecer-lhe o poder de competição, inclusive nos mercados externos, será objetivado através de:

- Estabelecimento decomplexo tecnológico naG uanabara, junto àU FRJ, na Ilha do Fundão, constituído de centros tecnológicos em setores de infraestrutura eindústrias básicas, a cargo notadamente deempresas governamentais. O s principais centros tecnológicosserão: Petróleo, Energia Elétrica, Pesquisa de Recursos M inerais, Energia N uclear, Siderurgia.

- Transferência, ao setor privado, dos resultados do Programa dePesquisa Industrial a ser implementado pela Secretaria deTecnologia Industrial do M IC e pelo Programa Especial deTecnologia Industrial (M PCG-CN Pq-BID ).

- Política de transferência de tecnologia do exterior baseada em:

- definição de setores prioritários segundo a natureza do produto e/ou do processo a ser importado e sua significação para o desenvolvimento nacional, e a possibilidade de solução interna do problema tecnológico; - esforço de redução dos custos da importação de tecnologia, com progressivo declínio do déficit em divisas do balanço tecnológico com o exterior;

- melhor conhecimento da oferta mundial detecnologia, afim depermitir ampla avaliação na escolha de alternativas e conferir maior poder de negociação às empresas nacionais, com a assessoria de entidades governamentais;

- utilização flexível do sistema mundial de patentes, visando a usufruir os benefícios que dele possam advir e evitando aqueles aspectos que se constituem em obstáculos ao desenvolvimento econômico;

- remoção dos obstáculos à absorção e difusão interna de tecnologia importada, através demedidastendentesa eliminar as restrições contratuais ou implícitas que possam acompanhar os acordos detransferência.

- Política destinada a reduzir os custos de elaboração da tecnologia. 0 principal instrumento a ser utilizado serão os incentivos financeiros que permitem desdobrar o custo da pesquisa ao longo do tempo, fortalecendo a capacidade de competição nacional. 
Estarão, portanto, abertas à empresa nacional as seguintes possibilidades: apoio financeiro governamental àsfundaçõese outras entidades depesquisasetoriais criadas pelo setor privado; financiamento de plantas-piloto para pesquisa de processos produtivos; financiamento de pesquisa e desenvolvimento, principal mente, de bens de capital; financiamento de compra de projetos de fabricação de bens de capital do exterior; financiamento para equipamentose obras civis para centros e laboratórios de pesquisas próprios; financiamento para solicitação de projetos de pesquisa a Institutos e Centros de Pesquisa; financiamento para cobertura degastos com formação de pessoal especializado; incentivos fiscais à importação de instalações, equipamentos e instrumentos, sem similar nacional, quando destinados à pesquisa.

O sfinanciamentos estarão baseados em recursos do FN DCT, da FIN EP e do BN DE (FIN AM E eFUN TEC, principal mente), contando com a colaboração de órgãos estaduais de desenvolvimento, como o Conselho Estadual de Tecnologia e o BADESP, de São Paulo, sempre que possível, enquanto que oS incentivos fiscais serão administrados pelo CD I. Entre seus provávés beneficiários deverão estar as empresas de consultaria, elo entre os sistemas econômico e técnico-científico.

- Política destinada a reduzir os riscos das inversões em pesquisas, principalmente pela expansão, garantia e previsibilidade da demanda, notadamente a do setor público, através de:

- adoção pelas empresas governamentais de uma política de preferência por aquisições debens decapital produzidosno País, a qual será conjugada à política de financiamento em condições internacionalmente competitivas, já em execução pela FIN AM E/BN DE, com oscomplementos que se façam necessários;

- montagem de laboratórios de pesquisa nas entidades governamentais e expansão dos já existentes, cujos serviços poderão ser utilizados também por outras empresas, criando assim economias de escala e evitando duplicação de serviços;

- encomendas das entidades governamentais aos institutos de pesquisa, estabelecendo os vínculos que devem existir entre o sistema produtivo eas entidades de pesquisa e ensejando a formação de uma "massa crítica" de pesquisadores com vivência tecnológica, cujos benefícios se irradiarão 
para os demais usuários dessas entidades; a atuação direta das empresas governamentais neste caso como no anterior, afigura-se de fundamental importância para aquelas atividades que estão sob controle predominante do G overno, notadamente as que afetam diretamente o nível de bemestar da população, como saúde, educação, habitação;

- estímulo das entidades governamentais às empresas privadas com as quais mantêm vínculos econômicos e financeiros, para que expandam sua demanda por tecnologia desenvolvida no País, quer na própria empresa quer por encomendas a entidades de pesquisa e consultoria aqui radicadas; a garantia de absorção pela entidade governamental de lotes experimentais será um forte incentivo à realização de pesquisas pela indústria nacional, o qual poderá ser conjugado aos mecanismos financeiros antes mencionados.

- Política de modernização da empresa privada nacional, quanto à tecnologia, à capacidade gerencial eà estruturafinanceira, através deinstrumentos como o Fundo deM odernização eR eorganização I ndustrial - FM RI, o Programa deM odernização e Reorganização da Comercialização - PM RC, do BNDE, eo Centro de Assistência Gerencial à Pequena e M édia Empresa - CEBRAE e 0 Programa deTreinamento em Administração, do M PCG .

- Política de apoio à engenharia nacional, segundo a legislação já em vigor, inclusive para efeito de venda de "know-how" no exterior.

- Engajamento da empresa estrangeira na política científica e tecnológica, particularmenteatravés do estabelecimento de orçamento próprio de pesquisa no País.

III - Consolidação da infra-estrutura de pesquisa científica etecnológica, principalmente na área governamental, através de:

- Fortalecimento institucional efinanceiro dos organismos de pesquisa considerados de al to interesse para os setores prioritários. N uma primeira seleção, no âmbito federal, já foram inicialmente destacadas instituições como: Instituto $\mathrm{N}$ acional deTecnologia; Instituto $\mathrm{N}$ acional de Propriedadel ndustrial; Instituto N acional de Pesos e M edidas; EM BRAPA, inclusive o sistema de institutos regionais de pesquisa agropecuária sob sua coordenação; D iretoria 
de Pesquisa e Ensino Técnico do Exército, inclusive os Institutos sob sua coordenação; Instituto de Pesquisas da M arinha; Centro T écnico Aeroespacial; Institutos vinculados ao CN Pq (IN PE, IM PA, IN PA, IBBD ); Centros de Pós$G$ raduação do M EC; Fundação Instituto $O$ swaldo $C$ ruz.

- Criação da nova carreira de pesquisador científico etecnológico, dentro do novo sistema de classificação de cargos, já estabelecido pelo D ecreto no $72.303 / 73$, e de novos níveis de remuneração, conforme projeto de lei encaminhado ao Congresso $\mathrm{N}$ acional pela $\mathrm{M}$ ensagem $\mathrm{n} 0161$, de 30/5/73.

- Política de Recursos H umanos para o sistema de pesquisa científica e tecnológica, em articulação com o sistema nacional de pós-graduação.

IV - Consolidação do sistema deapoio ao desenvolvimento científico e tecnológico, compreendendo, principalmente:

- Estabelecimento do Sistema N acional de Informação Científica e Tecnológica (incluindo a criação do Banco de Patentes), com as finalidades de:

- recolher e difundir documentação científica e técnica entre os demais segmentos do sistema científico e tecnológico e do setor produtivo;

- recolher informações sobrea oferta interna de tecnologia e o potencial das instituições de pesquisa, comunicando-as aos demais segmentos do sistema e ao setor produtivo;

- promover a difusão de informações sobrea disponibilidade externa de tecnologia livreepatenteada.

Para cumprir tais atribuições, o Sistema N acional de Informação Científica eTecnológica deverá estruturar-se de forma descentral izada em sua operação, tendo o CN Pq como seu órgão central.

- M odernização e expansão, já em curso, das atividades dePropriedade Industrial, M etrologia, N ormalização, Inspeção e Certificação de Q ualidade Industrial.

- Cooperação T écnica Internacional dirigida precipuamente para 0 fortalecimento das instituições nacionais e para projetos de maior dimensão e alta prioridade. 
V - Integração Indústria-Pesquisa-Universidade, impulsionada mediante:

- Disseminação e consolidação dos centros deintegração U niversidadeIndústria, para assegurar programas sistemáticos de estágios de estudantes em empresas, para comunicar ao sistema universitário as necessidades quantitativas equalitativas do setor privado quanto à formação de profissionais, epara permitir a realização conjunta de projetos de pesquisa.

- Real ização de programas conjuntos de pesquisa, em setores prioritários e em grande dimensão, com participação de instituições governamentais de pesquisa, universidadese setor privado, particularmentena área industrial.

- Adoção, pelas instituições de pesquisa governamentais, de programa sistemático dearticulação com o setor produtivo nacional, principalmentepara disseminação do resultado de seus estudos.

- Realização de convênios do G overno com as Universidades, paraque estas procedam a estudos de desenvolvimento regional ou a pesqui sas aplicadas, de interesse do planejamento econômico e social e da política científica e tecnológica.

- Ampliação dos esquemas de participação do estudantenos programas dêdesenvolvimento, a exemplo do Projeto Rondon, da 0 peração M auá, etc.

D eacordo com a orientação fixadano D ecreto 70.553/72, foram definidas as seguintesáreas de competência privativa na formulação e execução da Política $\mathrm{N}$ acional deD esenvolvimento Científico eTecnológico:

a) Conselho $\mathrm{N}$ acional de Pesquisas - CN Pq - assessoramento sob o ponto de vistacientífico-tecnológico;

b) M inistério do Planejamento e Coordenação G eral - assessoramento sob os aspectos econômico-financeiros, tendo em vista o entrosamento do desenvolvimento científico-tecnológico com a Estratégia Geral do $\mathrm{D}$ esenvolvimento $\mathrm{N}$ acional.

$\mathrm{N}$ a forma da sistemática estabelecida no mesmo texto legal, as atividades na área de C iência eTecnologia deverão organizar-se sob a forma de Sistema. D ele farão parte, sem prejuízo da subordinação ao órgão em cuja estrutura 
administrativa estiverem integradas, todas as unidades organizacionais de qual quer grau queutilizem recursos governamentais para realizar atividades de planejamento, supervisão, coordenação, estímulo, execução ou controle de pesquisas científicas etecnológicas.

A fim de possibilitar a coordenação das unidades componentes, deverão ser constituídos sistemas setoriais basicamente com os seguintes objetivos:

- formulação de diretrizes gerais de política de pesquisa em cada área correspondente;

- elaboração dos programas setoriais de pesquisas;

- acompanhamento de programas eprojetos setoriais específicos.

O M inistério do Planejamento e Coordenação Geral e o Conselho Nacional de Pesquisas - CNPq examinarão em conjunto os projetos de organização dosSistemasSetoriais, demaneira a ajustá-losentresi ea harmonizálos com a concepção básica do Sistema N acional, antes de sua aprovação final pelo G overno Federal.

O Sistema N acional, organizado de início na área da Administração Federal, deverá articular-se progressivamente com os Sistemas Estaduais, coordenando efforçose recursos. Será concedido apoio financeiro aos Sistemas Estaduais. 0 entrosamento com o setor privado, segundo formas que forem apropriadas, será estimulado a fim de proporcionar-se à empresa privada indicações sobre as prioridades e objetivos econômicos e sociais, bem como assegurar-Ihes o apoio que necessitarem.

A Academia Brasileira de Ciências terá ampliada a sua capacidade de assessoramento ao Sistema $\mathrm{N}$ acional de Ciência eTecnologia, principalmente com a coordenação e patrocínio de programas e projetos específicos, em prosseguimento à linha de ação iniciada com resultados promissores.

A efetivação do PLANO BÁSICO DE DESENVOLVIMENTO CIENTífIC O E TECNOLÓGICO - PBDCT, no período 1973/74, objetiva 0 impulsionamento, orgânico e sistemático, dessas áreas de atuação, através da ação coordenada dos diferentes $M$ inistérios.

Para a atuação orgânica do G overno, na conformidade do citado D ecreto 70.553/72, o PBD CT , elaborado segundo orientação emanada do Presidente 
da República, constitui trabalho de equipe, com a participação dos diferentes M inistérios, sob a coordenação do M inistério do Planejamento eC oordenação G eral, em articulação com o C onselho N acional de Pesquisas - CN Pq.

Sua execução ordenada e dentro dos prazos previstos está assegurada pelo esquema financeiro já definido, na forma do orçamento de Ciência eTecnologia apresentado no capítulo II.

As Partes II e III compreendem o elenco de projetos prioritários dos diferentes M inistérios, sem caráter de exaustividade e selecionados dentro da concepção de pesquisa apresentada no próximo capítulo. 